\title{
El tratamiento de los adjetivos de relación en el diccionario de la academia
}

\author{
Enríquez Jiménez Ríos \\ Universidad de Salamanca
}

\section{INTRODUCCIÓN}

La aplicación de la lingüística a la confección de diccionarios ha favorecido el desarrollo experimentado por la lexicografía en los últimos años ${ }^{1}$ y puede favorecerla mucho más en muchos aspectos del diccionario que están necesitados de contar con planteamientos lingüísticos explícitos y no con meras intuiciones. Es lo que ocurre con los adjetivos de relación, de cuyo tratamiento en el diccionario de la Academia me voy a ocupar en este trabajo, examinando su definición y la información pragmática que aparece en ellos, consciente de que este diccionario está destinado a servir como herramienta para la comprensión de un texto, más que para su producción. Sin embargo, no faltan muestras claras del deseo de ofrecer ese tipo de información, como vamos a ver más adelante. Antes de tratar esto, expondré brevemente cuál es la naturaleza de estos adjetivos, así como el procedimiento para su formación.

1 Tradicionalmente ha sido la semántica la disciplina lingüística que más ha intervenido en la elaboración de los diccionarios. En cambio, desde hace unos años se insiste en la aportación que la sintaxis, la morfología e, incluso, la pragmática, pueden ofrecer en el proceso de confección de los diccionarios, como han puesto de manifiesto, entre otros, Imbs (1969), Bosque (1982), Ettinger (1982), Ahumada (1987, 1988) y Pena (1994).

2 Cito por Bosque (1993:12).

Enrique Jiménez Ríos, "El tratamiento de los adjetivos de relación en el diccionario de la academia", 


\section{LA DEFINICIÓN DE LOS ADJETIVOS DE RELACIÓN}

Los adjetivos de relación son aquellos que indican la inclusión del sustantivo sobre el que inciden en una determinada clase o ámbito y son siempre restrictivos o especificativos. Demonte (1982:456) los explica así, señalando que dichos adjetivos están vinculados a sintagmas preposicionales — complementos de genitivo — que expresan relaciones de propiedad y que son parafraseables por construcciones del tipo "relacionado con", como refleja la definición que ofrecen algunos diccionarios como el DraE, el DGILE, el Clave, etc. Sin embargo, Pinchon (1980:91) considera que no siempre es posible cambiar el adjetivo por el complemento preposicional, ya que en muchos casos es el sustantivo al que acompañan el que obliga a una estructura o a otra, como vamos a ver más adelante. De esto se desprende que la equivalencia entre ambos sintagmas se da en muy pocos casos, lo que no se compadece con la postura que defienden los partidarios - como Postal $(1969)^{2}$ — de explicar estos adjetivos como resultado de una transposición o transformación ${ }^{3}$.

Por su parte, Bosque (1993:10) explica también que dichos adjetivos se caracterizan por no ser calificativos, sino por establecer conexiones con otros dominios o ámbitos externos a ellos, mediante las cuales sitúan o clasifican a los sustantivos a los que acompañan. Precisamente esa capacidad de restricción y esa conexión con otros dominios les viene dada por ser formas derivadas — en su mayoría - de sustantivos, ya que es posible crear un adjetivo de relación a partir de cualquier nombre, como vamos a ver en el apartado siguiente en el que se aborda la formación de este tipo de adjetivos.

3 Esto es lo que hace que no suelan ser intercambiables, por ejemplo, los sintagmas lavado de cerebro o batalla campal por los correspondientes sintagmas con adjetivo y complemento preposicional respectivamente, pues es probable que estemos ante nombres compuestos o compuestos sintagmáticos, como ha estudiado en el ámbito del español Rojo (1975), Bustos Gisbert (1986) y también menciona Bosque (1993).

4 Lo que no quiere decir que los adjetivos de relación se creen únicamente a partir de sustantivos, pues también puede hacerse a partir de adjetivos, como precisa Bosque 


\section{LA FORMACIÓN DE LOS ADJETIVOS DE RELACIÓN}

\subsection{AFIJOS QUE INTERVIENEN EN LA FORMACIÓN}

La principal característica de estos adjetivos es que son muy numerosos en español, precisamente porque, como apunta Varela (1992:16), cualquier hablante puede crearlos con facilidad haciendo uso de su propia competencia morfológica. De todo sustantivo se puede crear su correspondiente adjetivo de relación ${ }^{4}$; para ello basta con añadir a una base nominal cualquiera de los afijos capaces de formar un adjetivo de este tipo, de los que ofrece un examen detallado Santos (1995:364371). El más productivo, tanto sincrónica como diacrónicamente, es el sufijo -al que encontramos en voces como residencial (<residencia). A su lado otros sufijos que también crean este tipo de adjetivos son, como señala Lang (1992:198), -ario que aparece en parlamentario (<parlamento) y su variante -ero en traicionero (<traición), -ico en céntrico (<centro), -iego en veraniego (<verano), -il en estudiantil (<estudiante), -ista en petrarquista (<petrarca), -ivo en deportivo (<deporte), -(a,e,i,u)sco en canallesco (<canalla), etc. Las preferencias por unos u otros vienen dadas por los distintos valores que pueden adoptar, como vamos a ver a continuación.

\subsection{PRODUCTIVIDAD DE LOS AFIJOS Y VALORES QUE PUEDEN ADOPTAR}

El motivo que ha determinado la mayor productividad de algunos de estos sufijos, además del refuerzo de algunas variantes como resultado del prestigio que tienen en otras lenguas - como ha sucedido en inglés con $-a l^{5}$ - , ha sido la especialización que experimentan al adoptar sólo un valor relacional o también calificativo. Como apunta

(1993:11). E incluso adjetivos no denominales como rojo, amarillo, pueden funcionar como relacionales (Bosque, 1993:17).

5 En inglés hay formas que no tenemos en español, como, por ejemplo, peripheral, periodical, periodontal, etc., o al menos no las recogen los diccionarios manejados aquí. En otros casos, como sucede con lexical —a pesar de que tampoco aparece documentado en los repertorios léxicos- vemos que se está imponiendo a léxico, debido a los distintos sentidos que se le pueden atribuir a esta última palabra. 
Bosque (1993:20), en general, las formaciones adjetivas con los sufijos -al, -ario, -ico, -ista e -ivo son las que poseen el valor relacional, mientras que las que tienen -il, -iego, y -sco, son las que con más facilidad pueden adoptar, además, el valor calificativo como, de hecho, reflejan los diccionarios al caracterizar los adjetivos que tienen estos sufijos, como vamos a ver después. Sin embargo, estas obras no dan cuenta de estas diferencias al explicar el valor de cada uno de estos afijos ${ }^{6}$.

Esta distribución no impide, como señala, entre otros, Gawelko (1975:309), que algunos adjetivos de relación puedan, con el paso del tiempo, adoptar el valor calificativo, perdiendo incluso su valor relacional: es el caso de los formados con $-a l^{7}$. El paso de adjetivo de relación a calificativo no depende básicamente de que unos tengan un sufijo u otro, porque existen muchos casos en los que se produce la ambigüedad entre ambas interpretaciones ${ }^{8}$, como señala Bosque (1993:19), aunque existan ciertas regularidades. En cualquier caso, de

6 Así, por ejemplo, el diccionario de la Academia, en su última edición, explica que -al, -il 'significa generalmente relación o pertenencia'; -ario 'en los adjetivos indica relación con la base derivativa',-sco 'en los adjetivos suele denotar relación o pertenencia, y a veces tiene matiz despectivo'; -ico 'indica relación con la base derivativa', sin más explicación; -iego 'suele significar relación, pertenencia u origen'; etc. No ofrece, en cambio, en -ivo, sufijo de adjetivos deverbales, el valor que tiene en formas como la que he citado, deportivo, creada a partir de un sustantivo, y que puede funcionar como adjetivo relacional y calificativo. Son éstos también los valores que Lapesa (1975) asigna a los adjetivos.

Son, como puede observarse, explicaciones similares a la que ofrece Kalik (1967:283) para el francés. Este autor explica que -esque y -ien forman adjetivos que expresan la idea de posesión y pertenencia; -ien es sufijo con matiz positivo y -esque con matiz peyorativo; -isque sirve para expresar la pertenencia a una doctrina o escuela; y -el, -al son los más productivos.

7 Cordial ha tomado un valor calificativo y ha dejado el relacional para la forma cardíaco. Esta idea de especialización entre los sufijos la comparte también Bartos $(1995: 112)$ que habla del predominio de -oso para formar adjetivos calificativos y -al y -ario, -ero para los relacionales.

8 Como musical en sonido musical y crítica musical o gramatical en oración gramatical e investigación gramatical. Según expone Bosque (1993:11) los adjetivos musical y gramatical tienen una lectura calificativa en el primer ejemplo y relacional en el segundo. Esto confirma también lo que he señalado más arriba, tomado de Pin- 
esta situación deduce Bosque (1982:120) que

\begin{abstract}
quizá no deba ser objetivo del diccionario definirlos [los adjetivos] individualmente porque en todo ello interviene la extrema complejidad de los valores semánticos de los morfemas derivativos y su no pocas veces arbitraria relación con la sintaxis.
\end{abstract}

Lo cierto es que los diccionarios definen individualmente estos adjetivos, estableciendo en esa definición una relación con la base nominal de la que derivan. Su consulta en el diccionario académico - y en otros diccionarios del español, ya estén destinados a la codificación o descodificación de un texto-, pone de manifiesto que los repertorios léxicos y, en particular el académico, no proceden con un mismo criterio a la hora de definirlos, no organizan las acepciones de la misma manera en todos los casos y no ofrecen las indicaciones necesarias para hacer un uso adecuado de ellos, bien por medio de marcas o bien por medio de otro tipo de información complementaria, como vamos a ver en el apartado siguiente.

\title{
4. CRITERIOS PARA ORGANIZAR LOS ADJETIVOS DE RELACIÓN \\ 4.1. EL MODO DE LA DEFINICIÓN EN EL DICCIONARIO
}

El modo de redactar la definición morfológica que aparece en estos adjetivos es muy variado, ya que se recurre a ocho modelos distintos de definición: 'de', 'perteneciente a', 'perteneciente o relativo a', 'propio de', 'propio o peculiar de', 'relativo a', 'referente a', 'referente o relativo $a$ '. Parece que no hay, en principio, ningún motivo para preferir un modo de definición u otro, máxime cuando en el diccionario de la Academia se definen la mayoría de estos comodines definitorios enviando de unos a otros 9 . Un examen más detenido de los ejemplos muestra un principio de coherencia definitoria al utilizarse la fórmula "pertene-

chon (1980:91), acerca de la importancia que tiene el sustantivo al que acompaña el adjetivo.

9 Así, en la $21^{\mathrm{a}}$ edición del Dr a e, perteneciente, (de pertenecer) es 'tocar a uno o ser propia de él una cosa, o serle debida', 'referirse o hacer relación una cosa a otra, o 
ciente o relativo a" cuando el valor del adjetivo es relacional y "propio de" o "peculiar de" cuando es calificativo; por más que esta situación se complique cuando se considera la facilidad con que cualquier adjetivo de relación puede adoptar el valor calificativo 10 .

El examen de los datos revela que una fórmula abunda más que otra, como de hecho sucede con "perteneciente o relativo a". En el DGILE - como reflejan las ediciones del 90 y 93 - la que se utiliza es "relativo a". En cambio, en otros diccionarios el recurso para definir estos adjetivos es la fórmula "de+nombre base"11. Este modo de proceder, más sucinto, es más adecuado semánticamente que la fórmula "perteneciente o relativo a", por la variedad de sentidos que puede adoptar esta preposición; y también lo es lexicográficamente porque si consideramos la prueba de la sustituibilidad propuesta por Seco (1987:21) la mayoría de los adjetivos de relación pueden ser sustituidos por un sintagma preposicional ${ }^{12}$. Pero, de cualquier manera, tanto un modo de proceder como otro, lo único que hace en el plano lexicográfico es ligar la base con el derivado, lo que permite a los dicciona-

ser parte integrante de ella', relativo es 'que hace relación a una persona o cosa', referente, (de referir) es 'poner en relación personas o cosas', propio es 'perteneciente a uno que tiene la facultad exclusiva de disponer de ello', 'característico, peculiar de cada persona o cosa', 'referente a la misma persona que habla o a la persona o cosa de que se habla' y peculiar es 'propio o privativo de cada persona o cosa'.

10 Sin embargo esta distinción aparente puede decirse que no se cumple en el diccionario académico, puesto que, a excepción de voces como pueril en la que la primera acepción es 'perteneciente o relativo al niño' y la segunda, 'propio de niño', en otras voces ambas fórmulas se funden en una sola definición.

11 Es lo que sucede en el DuE de María Moliner, en el Larousse-Planeta, Salamanca y Vox-Alcalá. En el Clave la forma es "de+base o relacionado con ella". Las referencias bibliográficas de estos diccionarios aparecen al final del artículo.

12 Como señalan algunos de los estudios gramaticales a los que me he referido más arriba, a excepción de las precisiones hechas por Pinchon (1980:91). Además con este procedimiento se solucionan los posibles problemas que pueden derivarse de parafrasear con "perteneciente o relativo a" los adjetivos de relación argumentales o temáticos, como expone detalladamente Bosque (1993:15).

13 Hay alguna excepción, como hemorroidal, recogido en el Drae con marca Pat. y definido como 'perteneciente a las almorranas. Arteria, sangre hemorroidal; venas 
rios colocar estos adjetivos bajo el lema base, ordenando así — como hace, por ejemplo, el DuE, aunque no en la nueva edición - las voces en familias de palabras. Pero este recurso también sirve para dar cuenta de lo que, en realidad, es información etimológica y no únicamente de la definición, pues como señala Seco (1987:17):

no siempre la ausencia del paréntesis etimológico obedece a desconocimiento; se omite, por economía, siempre que queda puesto en evidencia el étimo en la propia definición, como ocurre, por ejemplo, en palaciego 'perteneciene o relativo al palacio' 13 .

Pero, si el significado de los adjetivos de relación es fácilmente deducible, a pesar de estas diferencias en la definición, no sucede lo mismo con su comportamiento contextual y con sus posibilidades combinatorias. Sobre este hecho ya llamó la atención Bosque (1982:120) al señalar que:

mientras no hay duda de que estas definiciones son suficientes para reconocer el significado de dicho adjetivo, no lo son para usarlo apropiadamente. Sin más especificaciones formaríamos sintagmas como libros estudiantiles, pupitres estudiantiles, o exámenes estudiantiles,

ya que de nada sirve definirlos como se hace en los siguientes ejemplos, que sólo tienen el significado que corresponde a la acepción relacional, fácilmente deducible por los hablantes y, que pertenece, como acabamos de ver en Seco (1987:17), más al dominio de la etimología que al de la definición:

arañil: 'propio de la araña o perteneciente a ella'.

bribonesco: 'perteneciente o relativo al bribón' 14 .

climático: 'perteneciente o relativo al clima'.

hemorroidales'. Como no aparece en la definición la voz hemorroide, entonces en el apartado dedicado a la etimología remite a la base derivativa.

14 En el DrAE se recoge por primera vez en la $21^{\mathrm{a}}$ edición.

15 Aunque también es probable que en ello intervenga o bien la diferencia de que sean formaciones de creación reciente, o adjetivos ya existentes en latín, como sucede 
detectivesco: 'referente o relativo al detective o a su profesión'. escribanil: 'perteneciente al oficio o condición del escribano'. jergal: 'propio de una jerga'. muchachil: 'de muchachos o propio de ellos'.

Por este motivo quizás lo más conveniente sería que sólo se recogieran en el diccionario los adjetivos que tienen otras acepciones que no son deducibles — calificativas, por tanto-, además de la relacional — como se ha hecho ya con otras clases de palabras como los participios de pasado y con los adverbios terminados en -mente-, o los que tienen simplemente una definición distinta a la relacional, como sucede en los siguientes ejemplos, en los que no hay adjetivos de relación, sino calificativos 15 :

eternal: 'que no tiene fin' 16 .

final: 'que remata, cierra o perfecciona una cosa'.

legañil: p.us. 'que tiene muchas legañas'.

testimonial: 'que hace fe y verdadero testimonio'.

torrencial: 'parecido al torrente'.

Otra posibilidad que habría que considerar para el tratamiento de estos adjetivos - y para dejar claro si sólo tienen valor relacional o también calificativo - es dotarlos de marcas o de otro tipo de información complementaria, lo que no puede decirse que no se haya hecho nunca, pues en algunos casos, cuando dejan de ser simples adjetivos de

con aeternalis, finalis, etc; o bien casos en los que se dé ambigüedad como reconoce Bosque (1993:15) entre el valor relacional y el calificativo. La prueba para su consideración como calificativos está en la existencia de un sustantivo derivado en -idad: eternidad, finalidad. Pero su no existencia no implica que no pueda tener valor calificativo como apunta también Bosque (1993:18): "la existencia de este sustantivo no es, sin embargo, imprescindible para que se dé la interpretación calificativa”.

16 Es un arcaísmo recuperado por vía del inglés o del francés, del que no se ofrece ninguna información adicional en el DrAE. Más precisos son el DGILE'90 y el DGILE'93 que explican que es poco usado y que pertenece al estilo solemne respectivamente y el Clave que lo marca como de uso poético.

17 En el diccionario académico aparece carencial: Med. 'perteneciente o relativo a la carencia de sustancias alimenticias o de vitaminas' y carencia: Med. 'falta de deter- 
relación, sí encontramos este tipo de precisiones, como vamos a ver en el apartado siguiente en el que se analiza el modo como se inserta en el diccionario académico este tipo de información pragmática y contextual.

\subsection{LA PRESENCIA DE MARCAS Y DE INFORMACIÓN CONTEXTUAL}

\subsubsection{Adjetivos de relación con marcas}

Uno de los recursos para restringir el uso de los adjetivos de relación es colocar en sus entradas marcas diatécnicas, diacrónicas o diafásicas. Las marcas, cuando son diatécnicas, son una muestra más de la ligazón que se establece entre la base y el derivado, aunque hay veces en que sólo una de las dos palabras tiene marca ${ }^{17}$. En cambio, el significado y el valor de las marcas diacrónicas y diafásicas es muy distinto al de las anteriores, porque las diacrónicas reflejan el desuso de los adjetivos con un determinado afijo, como sucede en los siguientes ejemplos:

damil:ant. 'perteneciente a las damas o propio de ellas'.

doncellil: fam. desus. 'propio de las doncellas o a ellas referente' 18 .

lacayil: desus. 'propio de lacayos, lacayuno'.

mocil: p.us. 'propio de gente moza'.

patronil: desus. 'perteneciente o relativo al patrón o dueño de una casa',

$\mathrm{y}$, por consiguiente, también sirven para mostrar las preferencias por formas con otros afijos, como sucede, por ejemplo, con legañoso que

minadas sustancias en la ración alimenticia, especialmente vitaminas'. En cambio, llama la atención que en el Dgil e'90 y Dgil e'93, carencial se defina como Med. 'relativo a la carencia' y que carencia aparezca sin marca como 'falta o privación de alguna cosa', lo que no es exclusivo de estos diccionarios porque en el Dr ae hay casos en los que la base tiene marca y el derivado no, como sucede, por ejemplo, con circunferencia y circunferencial.

18 En el DGiLE'90 y DGiLE'93, con marcas familiar y desusado, 'propio de doncellas'.

19 Pero hay también casos, como sucede en el Diccionario de Autoridades, en el que la voz caballerilmente, adverbio formado a partir de un adjetivo de relación, está marcado como anticuado y remite a caballerosamente, adverbio formado sobre un 
sustituye a legañil, lacayuno a lacayil y filosófico a filosofal ${ }^{19}$. Por su parte las marcas diafásicas lo que hacen es ofrecer una información pragmática importante para su uso adecuado, y es la marca familiar la que suele aparecer, como vemos en los adjetivos siguientes:

abogadil: $\underline{\text { despec. }}$ 'perteneciente a los abogados. No es despectivo en Costa Rica'.

barberil:fam. 'propio de los barberos'.

cocheril: fam. 'propio de los coches y de los cocheros'.

curanderil: fam. 'perteneciente o relativo al curandero y a sus procedimientos'.

doncellil: fam. desus. 'propio de las doncellas o a ellas referente'.

fregonil: fam. 'propio de fregonas'.

mosqueteril:fam. p.us. 'perteneciente a la mosquetería de los antiguos corrales de comedias'.

Lo que se desprende de la existencia de marcas en estos ejemplos es que su presencia trae consigo el cambio en la definición - $\mathrm{O}$ al menos esa parece la tendencia_-, ya que aparece la fórmula "propio de", que se he caracterizado como la que se utiliza para mostrar el valor calificativo de los adjetivos, motivada también proque estos adjetivos tienen un sufijo distinto a -al, lo que se compadece bien con lo señalado antes a propósito del valor asignado a los sufijos 20 . Un comportamiento similar al de estas formas con -il es el de las que tienen el afijo -sco, ya que en estos adjetivos también son abundantes las marcas de carácter diafásico o la existencia de una información adicional pragmática al

adjetivo calificativo. En cambio, sucede lo contrario en feminal, voz desusada, que remite a femenil, forma documentada hoy en el diccionario.

20 Sin embargo también es cierto que no todos los diccionarios mantienen estas posibles diferencias, como se comprueba al consultar, por ejemplo, el DuE: cocheril 'de los coches y de los cocheros', damil 'de las damas', muchachil 'de significado deducible del de muchacho', etc.

21 Sin marca en el Dgil e'90 y Dgil e'93.

22 Cf. la definición tan diferente que da, por ejemplo, el Diccionario Salamanca: 'que no tiene algunas sustancias necesarias para el organismo'. 
final de la definición, como puede verse en los siguientes ejemplos: abogadesco: 'perteneciente o relativo al abogado o a su profesión. Ú. por lo común en sentido despectivo'.

curialesco: 'propio o peculiar de la curia. Suele tomarse en mal sentido. Estilo curialesco, sutileza curialesca'. frailesco:fam. 'perteneciente o relativo a los frailes'. 21 memorialesco:fest. 'perteneciente o relativo al memorial. Estilo memorialesco'.

oficinesco: 'perteneciente a las oficinas del Estado, o propio y característico de ellas. Se usa generalmente en sentido peyorativo'. sacristanesco: despec. 'perteneciente o relativo al sacristán'.

Cuando faltan las marcas, otro tipo de informaciones proporciona la precisión de los adjetivos, como vamos a señalar a continuación.

4.2.2. Adjetivos con información sobre su comportamiento contextual y sintagmático

Dentro de este apartado de adjetivos con información de uso, los hay que poseen, junto con la definición, restricciones sobre su uso contextual o sintagmático, expuesta de tres modos distintos: por medio de complementos en el interior de la definición, por medio de la fórmula "dícese" o "aplícase" y del envío a locuciones o colocaciones en las que suelen aparecer estos adjetivos.

\subsubsection{Por medio de complementos en el interior de la definición}

Se trata de indicaciones semánticas que aparecen en el interior de la definición y que tienen la función de restringir las posibilidades combinatorias de los adjetivos. Su presencia muestra que el valor de adjetivo es ambiguo entre relacional y calificativo, a pesar de su definición, como vemos en ejemplos como los siguientes:

carencial: Med. "perteneciente o relativo a la carencia de sustancias

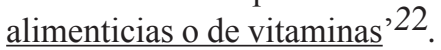

23 En el Diccionario Salamanca se define 'Del trabajo, en su aspecto económico, jurídico y social', explicaciones que no aparecen, por ejemplo, en el DGILE'90 y DGILE'93 
laboral: 'perteneciente o relativo al trabajo, en su aspecto económico, jurídico y social ${ }^{23}$.

novelesco: 'propio o característico de las novelas'.// 'Tómase generalmente por fingido o de pura invención, como historia novelesca; por singular o interesante, como lance novelesco; o por exaltado, sentimental, soñador, dado a lo ideal o fantástico, persona, imaginación novelesca, 24 .

pasional: 'perteneciente o relativo a la pasión, especialmente amorosa $^{25}$.

Son más numerosos en el DraE los casos en los que la restriccion contextual se hace por medio de la fórmulas "dícese", "aplícase", como vamos a ver en el apartado siguiente, en el que este recurso sirve también para destacar el valor calificativo de estos adjetivos.

4.2.2.2. Por medio de la fórmula “dícese”, “aplícase”, etc.

Pertenecen a este grupo algunos de los adjetivos que el diccionario académico recoge con una definición introducida por la forma "dícese" o "aplícase", las cuales sirven también para ofrecer la información contextual necesaria para emplear adecuadamente este tipo de adjetivos, como señala Seco (1987:25) a propósito de la definición de los adjetivos. En la definición aparece la unidad léxica con la que debe ir o a la que se aplica la voz definida:

califal: 'dícese de la época en que reinaron los califas, o de lo perteneciente a ellos'.

campesino: 'dícese de lo que es propio del campo o perteneciente a él'.

en los que hay un ejemplo para mostrar su uso.

24 Cf. la primera acepción del Diccionario Salamanca 'de la novela'.

25 Cf. la definición del Diccionario Salamanca: 'que tiene o manifiesta una gran pasión, especialmente amorosa'.

26 En la entrada eminencia no hay ninguna acepción marcada como Fil., por lo que puede concluirse que el adjetivo eminencial sólo aparece en el sintagma virtud eminencial.

27 Aquellos diccionarios que no recurren al uso de "dícese" o "aplícase", como el DGILE 
eminencial:Fil. 'aplícase a la virtud o poder que puede producir un efecto, no por conexión formal con él, sino por una virtud superior que le abraza con excelencia'26.

goliardesco: 'perteneciente o relativo al goliardo. Dícese especialmente de las poesías latinas compuestas por goliardos sobre temas amorosos, báquicos y satíricos'.

lagrimal: 'aplícase a los órganos de secreción y excreción de las lágrimas'.// V. Anat. fístula lagrimal, carúncula lagrimal.

Como puede apreciarse en estos ejemplos, la finalidad de este recurso metalingüístico es indicar el sustantivo o sustantivos a los que suele acompañar 27 . Una función similar cumplen las locuciones o colocaciones a las que remiten muchos de estos adjetivos, de las que me voy a ocupar a continuación.

\subsubsection{Por medio del envío a colocaciones y locuciones}

Los ejemplos pertenecientes a este grupo tienen el modelo definitorio 'perteneciente a'o 'perteneciente o relativo a' y se caracterizan también por la falta de información complementaria, ya que en muy pocos casos hay marcas, lo que permite concluir que su valor es el relacional. Sin embargo, a diferencia de los ejemplos que hemos visto hasta ahora, este grupo tiene la particularidad de enviar a una locución que, al mismo tiempo, sirve para mostrar el sustantivo con el que suele aparecer con más frecuencia y cumple una función similar a la de los ejemplos con los que se avala el uso de una voz:

bautismal: 'perteneciente o relativo al bautismo'. // V. pila bautismal.

cenital: 'perteneciente o relativo al cenit'. // V. ángulo, luz cenital.

diferencial: 'perteneciente a la diferencia de las cosas'. // V. derecho diferencial // V. cálculo diferencial

o el Diccionario Salamanca, se sirven de otros procedimientos como es colocar entre paréntesis cuadrados los nombres con los que suele ir el adjetivo. De este recurso habla también Seco (1987:28) en el apartado que acabo de citar.

28 Entendidas del siguiente modo, como explica Cruse (1986:40): "the term collocation will be used to refer to sequences of lexical items which habitually co-occur, but which are nonetheless fully transparent in the sense that each lexical constituent is also semantic constituent such expresions as (to pick a semantic area at random) fine weather, torrential rain, light drizzle, high winds are examples of collocations". 
facial: 'perteneciente al rostro'. // V.Anat. ángulo facial.

marcial: 'perteneciente a la guerra'. // V. flamen, ley, pirita marcial. obsidional: 'perteneciente o relativo al sitio de una plaza'. // V. corona, línea, moneda obsidional.

occipital: 'perteneciente o relativo al occipucio'. // Anat. V. ángulo occipital // Anat. hueso occipital.

pascual: 'perteneciente o relativo a la Pascua'. // V. ciclo, cirio, cordero pascual.

termal: 'perteneciente o relativo a las termas o caldas'. // V. agua termal'.

terrenal: 'perteneciente a la tierra, en contraposición de lo que pertenece al cielo'. // V. paraíso terrenal.

triunfal: 'perteneciente al triunfo'. // V. arco, carro, corona triunfal. vertebral: 'perteneciente a las vértebras'. // V. columna vertebral.

Este comportamiento de los adjetivos lleva a considerar la necesidad de establecer distintos grupos de adjetivos de relación, de acuerdo con su presencia en estructuras en las que se dé una mayor o menor lexicalización o fijación, como sucede en los siguientes casos, en los que el adjetivo sólo existe en una locución o colocación 28 :

campal: desus. 'perteneciente al campo'.// Mil. V. batalla campal.

comunal: común // V. bienes comunales. // ant. V. derecho comunal.

// (...) Amér. 'perteneciente o relativo a la comuna'.

coronal: Anat. V. hueso coronal. // 'perteneciente o relativo a este

hueso'.

Por otra parte, es interesante tener en cuenta la caracterización que hace Hausmann (1979) al señalar que la colocación es una combinación restringida y orientada, de manera que, por ejemplo, torrencial dirige u orienta a lluvia (cito por Alonso Ramos (1994:25).

29 Los diccionarios Salamanca y Clave sólo explican en esta voz que se usa en la locución válvula mitral.

30 Uno de los grupos de voces en que se recurre a ellos, aunque no de una manera sistemática, es precisamente el de los adjetivos de relación. Vid., por ejemplo, zodiacal: 'perteneciente o relativo al zodiaco, estrellas zodiacales'. // V. luz zodiacal,' así como otras voces que he citado a lo largo del artículo. 
filosofal: V. piedra filosofal. // ant. 'perteneciente o relativo a la filosofía'.

hiemal: p.us. invernal. // Astrol. V. cuadrante hiemal // Astron. V. solsticio hiemal.

mitral: Zool. V. válvula mitral ${ }^{29}$.

pineal: V. glándula pineal.

yugular: Anat. V. vena yugular.

Esta aparición en determinados sintagmas es lo que ha hecho que Bosque (1982:120) afirme que

la etiqueta 'perteneciente o relativo a' suele ocultar que los llamados adjetivos de relación aparecen sintácticamente en entornos no pocas veces estereotipados [...] Con todo, en algunos casos al menos, tal vez pudiera añadirse, como se hace ya en algunas solidaridades léxicas, cierta información contextual que restringiera la aplicación de las definiciones citadas;

opinión que comparte Bartos (1995:115), quien también señala que:

los adjetivos desustantivales que expresan relación o pertenencia son compatibles con un número bastante reducido de sustantivos núcleo: solar en sistema solar, manchas solares; carnal en amor carnal, acto carnal [...] o a un sólo sustantivo: batalla campal.

La conclusión que podemos extraer de todo esto es que, si la presencia de ejemplos en un diccionario sirve para informar sobre su comportamiento contextual, en un diccionario como el de la Academia, tan escaso de ejemplos 30 , la función reservada a ellos habrá que otorgarla a este tipo de colocaciones. Sólo por medio de los ejemplos y de la remisión a estas locuciones podremos saber que adjetivos como

31 Esto encuentra una explicación en la siguiente afirmación de Bosque (1993:31): "un adjetivo no denota una cualidad o una clase de forma inherente, sino de manera relativa a las condiciones extralingüísticas que se consideran relevantes en cada tipo de discurso. Nótese que un adjetivo tan claramente calificativo como amoroso es relacional en estrategias amorosas o literatura amorosa. Ello es posible porque el amor no sólo puede concebirse como un sentimiento o una disposición (calificativo), sino también como un dominio o un ámbito y ésta es la categorización que la lectura 
filosofal e hiemal — por poner un ejemplo- ya anticuados, se conservan en las colocaciones piedra filosofal y cuadrante y solsticio hiemal, respectivamente. Con anterioridad a los autores que he citado más arriba, Fernández Ramírez (1986:82) también llamó la atención de este tipo de estructuras al afirmar que:

existen en el adjetivo agrupaciones que podemos denominar indisolubles, es decir, locuciones que son correlativas de un concepto y que no se pueden enunciar parcialmente sin alterar el objeto de la mención: pena capital, ciencia experimental, día festivo.

De ahí que los diccionarios deberían intentar enumerar los sustantivos con los que suelen aparecer con más frecuencia este tipo de adjetivos; de hecho esa es la función de estas colocaciones e incluso de la inserción de ejemplos en algunos casos. Cuando las posibilidades combinatorias sean muchas, es decir, cuando un adjetivo de relación pueda acompañar a muchos sustantivos, es probable que estemos ante adjetivos que estén adoptando el valor calificativo, como vamos a mostrar en el apartado siguiente ${ }^{31}$.

\section{SITUACIÓN DE LOS ADJETIVOS DE RELACIÓN QUE ADOPTAN EL VALOR CALIFICATIVO}

En los adjetivos de relación que adoptan el valor calificativo y que recogen ese valor en el diccionario académico se organizan las acepciones de una manera particular y ofrecen definiciones distintas a la fórmula "perteneciente o relativo a": se trata de las que tienen "dícese" o "aplícase", grupo al que ya me he referido más arriba, y de aquellas

relacional necesita para poder ser viable".

32 Cf. un diccionario de fuera del dominio lingüístico del español, como el Petit Robert, s.v. fenomenal en el que se explica que es 'Didact. De la nature du phénomène, du fait sensible (Kant: Monde phénomenal et monde noumenal)', lo que permite considerar arcaica la primera acepción que ofrece el Drae para este adjetivo y comprobar la escasez de marcas que tiene el Dr a e en algunos casos. Una prueba de ello la tenemos en que otros diccionarios, como el Salamanca, Clave, etc. no recojan ya esa acepción.

33 Es interesante ver cómo marcan los diccionarios las acepciones que dan cuenta del 
otras que tienen una definición distinta a estos modelos definitorios.

\subsection{ORGANIZACIÓN DE LAS ACEPCIONES DE ESTOS ADJETIVOS}

Como he señalado al comienzo de este trabajo, muchos adjetivos relacionales pueden adoptar con el paso del tiempo el valor calificativo, lo que lleva a distinguir, como hace Demonte (1982:468), acepciones de adjetivos con valor calificativo y acepciones con valor relacional; se trata pues de polisemia más que de homonimia. Cuando los adjetivos están en esta situación, el DRAE ofrece como primera acepción la relacional, que podemos caracterizar como anticuada o fosilizada en alguna colocación o estructura similar a las que hemos visto más arriba; a su lado aparecen las que hoy son más usuales, como reflejan los siguientes ejemplos, en los que se aprecia la diferencias de frecuencia de uso entre unas acepciones y otras:

esencial: 'perteneciente a la esencia'. El alma es parte esencial del hombre. // 'sustancial, principal, notable'. // V. aceite, fiebre, parte esencial.

fenomenal: 'perteneciente o relativo al fenómeno'. // 'que participa de la naturaleza del fenómeno,32. // fam. 'tremendo, muy grande'. Un cuello de puntas fenomenales. // fig. 'estupendo, admirable, muy bueno' Es un chico fenomenal // 'estupendamente'. Lo pasamos fenomenal aquella tarde ${ }^{33}$.

ideal: 'perteneciente o relativo a la idea'.// 'que no es físico, real y verdadero, sino que está en la fantasía'.// V. belleza ideal. // 'exce-

valor relacional y las del valor calificativo: para los calificativos en el DRAE se usa la marca fam.; en el DGILE familiar y figurado. Lo que nos lleva a pensar si no sería, acaso, más adecuado figurado que familiar, para explicar el cambio de relacional a calificativo, o lo que es lo mismo de sentido recto o primitivo a figurado.

34 No hay en el Dr ae una acepción que recoja el valor de esta voz en un enunciado como Es una persona muy visceral. En cambio en otros diccionarios sí: por ejemplo, en el Diccionario Salamanca la primera acepción, relacional, tiene marca anat.; la segunda, en cambio, es '[impresión, sentimiento] que es intenso, profundo y arraigado' y la tercera 'que muestra sus sentimientos de una manera intensa y apasionada'.

35 Otro grupo de adjetivos en los que la definición relacional va al final de la entrada lexicográfica es el de los gentilicios.

36 A cualquiera de las 47 acepciones que tiene la voz punto. Esta observación se debe 
lente, perfecto en su línea'.

visceral: "perteneciente o relativo a las vísceras'34.

Claro que también hay algunos casos, aislados, en los que, con un criterio innovador para este diccionario, la definición morfológica relacional aparece en último lugar, algo que ya hemos visto en algunos ejemplos citados anteriormente ${ }^{35}$, y se observa en las siguientes voces:

decimal: 'aplícase a cada una de las diez partes iguales en que se divide una cantidad'.// 'perteneciente al diezmo'.

heterosexual: 'dícese del individuo que practica la heterosexualidadí // 'dícese de la relación erótica entre individuos de diferente sexo'.// 'perteneciente o relativo a la heterosexualidad'.

homosexual: 'dícese del individuo afecto a la homosexualidad'.// 'dícese de la relación erótica entre individuos del mismo sexo'. // 'perteneciente o relativo a la homosexualidad'.

hospitalario: 'aplícase a las órdenes religiosas que tienen por norma el hospedaje'. // 'que socorre y alberga a los extranjeros y necesitados'. // 'dícese del que acoge con agrado o agasaja a quienes recibe en su casa y también de la casa misma'. // 'perteneciente o relativo al hospital para enfermos'.

puntual: 'pronto, diligente, exacto en hacer las cosas a su tiempo y sin dilatarlas'. // 'indubitable, cierto'. // 'conforme, conveniente, adecuado'. // 'perteneciente o relativo al punto, 36 .

rectangular: 'que tiene forma de rectángulo'.// Geom. 'pertenecien-

precisamente a la apreciación que hace Bosque (1982:120) cuando señala que "no puede decirse, a propósito de diurno, que todo lo "perteneciente al día" sea diurno, ni que todo lo "perteneciente o relativo a la guerra" sea guerrero".

37 En este ejemplo y en lo que sigue utilizo la doble barra // para separar las distintas acepciones de las voces.

38 En las tres voces encontramos en el Dgil e las mismas definiciones que en el Drae. Sobre el paso de adjetivos calificativos a relacionales y de relacionales a calificativos, vid. también Bartos (1995:112).

39 En el Diccionario Salamanca se explica que tiene valor intensificador y se define como 'que es una excepción o que ocurre rara vez'. // intensificador: 'que es mejor de lo normal o que tiene importancia única'. 
te o relativo al ángulo recto'// (...) Geom. 'perteneciente al rectángulo'.

sinovial: 'dícese de las glándulas que secretan la sinovia y de lo concerniente a ella'.

textil: 'dícese de la materia capaz de reducirse a hilos y ser tejida'.// 'perteneciente o relativo a los tejidos'.

unipersonal: 'que consta de una sola persona'.// 'que corresponde o pertenece a una sola persona, 37 .

Pero esta situación no es exclusiva del diccionario académico, pues se observa también en otros repertorios lexicográficos confeccionados con criterios más innovadores, como el DGILE:

decimal: 'parte que junto con otras nueve iguales constituye una cantidad'. (...) 'relativo al diezmo'.

procesional: 'ordenado en forma de procesión'. // 'relativo a ella'.

unipersonal: 'que consta de una sola persona'. // 'relativo a una sola persona'.

Claro que la necesidad de establecer esta distinción polisémica desaparece cuando, como ya he apuntado, una misma raíz puede llevar dos afijos distintos (como caballuno-caballar, cívico-civil, paternalpaterno, provinciano-provincial, musculoso-muscular, etc., en los que la primera forma es utilizada hoy con valor calificativo y la segunda con el relacional). Al lado de esta organización de las acepciones en el diccionario, existen otros recursos para mostrar el predominio del valor calificativo y el paso a un segundo plano del relacional, como vamos a ver a continuación.

\subsection{OTROS RECURSOS PARA MOSTRAR EL VALOR CALIFICATIVO}

La diferencia entre las acepciones relacional y calificativa de un mismo adjetivo se manifiesta en su comportamiento sintáctico; pero, sobre todo, en su significado. Este último se supedita al primero por-

40 La información contextual que aparece es tan amplia que, en verdad, sirve para poco: qué otros referentes se le puede aplicar el adjetivo además de a personas, cosas, sucesos, etc.? Parece que no es necesaria esta precisión, como hacen otros diccionarios. 
que, como señala Bosque (1993:39):

una de las propiedades fundamentales de los adjetivos de relación es el simple hecho de que su interpretación semántica no es "intrínseca", sino que depende de su relación posicional con el núcleo al que complementan. Los adjetivos de relación significan, pues, por el lugar que ocupan.

Pero hay casos en los que el significado del adjetivo cambia precisamente porque deja de ser adjetivo de relación y no porque esté en una posición u otra. El caso más claro lo representan los adjetivos que tienen otros sufijos — como -oso o -iento, etc. - en los que la mayoría ha perdido el valor relacional pasando a ser calificativos: así, ocioso, esponjoso, mugriento, polvoriento, etc. son claros adjetivos calificativos, en los que los diccionarios no recogen una acepción del tipo 'perteneciente a', ni tampoco 'propio de' o 'relativo a'. Pero no sólo ha sucedido esto en los adjetivos con esos afijos, sino que también se ha producido en algunos que tienen -al, como explica el tratamiento que han recibido los siguientes 38 :

descomunal: 'extraordinario, monstruoso, enorme, muy distante de lo común en su línea'.

excepcional: 'que constituye excepción de la regla común'.// 'que se aparta de lo ordinario, o que ocurre rara vez' 39 .

sensacional: 'aplícase a personas, cosas, sucesos, etc., que llaman poderosamente la atención, 40 .

41 Hay más detalles acerca de las diferencias sintácticas entre los adjetivos calificativos y relacionales en Bosque (1993:34-35) y en Santos (1995), en particular, se trata del deslinde y la subclasificación en la anteposición, de la jerarquía sintáctica de los relaciones entre sí — pues no todos se comportan igual — y la capacidad e incapacidad para formar adverbios en -mente.

42 Como hemos visto que hacen el Dgil e, el Diccionario Salamanca, el Clave, el VoxAlcalá, etc. en los que aparecen siempre ejemplos.

43 Cumpliendo así con lo expuesto en las Advertencias para el uso del diccionario en donde se dice que "dentro de cada artículo van colocadas por este orden las diversas acepciones de los vocablos: primero las de uso corriente; después las anticuadas, las familiares, las figuradas, las provinciales e hispanoamericanas y por último las técni- 
Estos adjetivos con valor calificativo, a pesar de haberse formado igual que otros con valor relacional, no presentan ninguna acepción que los relacione con el sustantivo que ha servido de base, como lo demuestran también los siguientes ejemplos extraídos del DRAE, a pesar de que aparezca la palabra base en el interior de la definición:

confidencial: 'que se hace o se dice en confianza o con seguridad recíproca entre dos o más personas. Carta confidencial'.

crucial: 'en forma de cruz. Incisión crucial'. //. 'dícese del momento o trance crítico en que se decide una cosa que podía tener resultados opuestos'.

especial: 'singular o particular, que se diferencia de lo común, ordinario o general'.

general: 'común y esencial a todos los individuos que constituyen un todo, o a muchos, aunque sean de naturaleza diferente'.

literal: 'conforme a la letra del texto o al sentido exacto y propio, y no lato ni figurado, de las palabras empleadas'.

servicial: 'que sirve con cuidado, diligencia y obsequio'.

subliminal: 'carácter de aquellas percepciones sensoriales, u otras actividades psíquicas, de las que el sujeto no llega a tener conciencia'.

Precisamente por no ser relacionales estos adjetivos no llevan en el Diccionario Salamanca la definición "de+nombre base”, característica de los adjetivos relacionales en este diccionario, sino otra muy distinta:

fatal: 'que causa desgracia o que perjudica a una persona o cosa'.

frugal: elevado 'que es poco abundante o moderado'.

genial: 'que tiene genio o talento creador'. // 'que contiene o está hecho con habilidad o destreza'. // 'que tiene ingenio o que es original'.

literal: 'que es fiel a la letra del texto o a su sentido exacto y propio, y no lo interpreta'.

subliminal: 'que ocurre por debajo del umbral de la conciencia'.

Y a diferencia de los adjetivos de relación estos adjetivos cumplen las pruebas sintácticas necesarias para caracterizarlos como calificativos, ya que pueden ir - simplificando y generalizando mucho las 
cosas, pues en esto interviene el sustantivo al que acompañan que es el que determina el valor relacional o calificativo - antepuestos o pospuestos al núcleo, llevar adverbios y que en ellos sea posible la gradación 41 . En todos ellos la referencia a la base derivativa ha quedado reducida a la parte dedicada a la etimología.

\section{CONCLUSIONES}

Lo que acabo de exponer en este último apartado revela la facilidad con que un adjetivo de relación puede convertirse en calificativo, situación más evidente aún cuando en ello intervienen diferencias afijales, como las que he tratado al comienzo de este trabajo, así como la dificultad para deslindar los adjetivos que sólo tienen valor relacional de los que sólo lo tienen calificativo. Para ese cambio sólo es necesaria una transposición semántica. De todos estos cambios y de la ambigüedad entre los dos valores han de dar cuenta, ciertamente, los diccionarios, por lo que en muchos casos la explicación "perteneciente o relativo a" es simplificar mucho la realidad de su uso. En este terreno no basta con poner en práctica unos criterios meramente lexicográficos, sino que también hay que considerar criterios gramaticales, lo que reclama la participación de otros ámbitos de la lingüística en la confección de los diccionarios.

A lo largo de estas páginas he examinado la situación que ofrece el diccionario académico que, a pesar de su carácter normativo y de su apego a la tradición, ofrece en algunos casos muestras claras de atender a las necesidades que tienen los usuarios que recurren a él y de reflejar adecuadamente los cambios que acabo de señalar: me refiero al hecho de que sea precisamente esta parcela de los adjetivos de relación un grupo en el que se adopta una actitud decidida para dar información

cas y de germanía." (p. XXV).

44 "Tampoco se incluyen todos los adverbios en -mente, ni todos los diminutivos y despectivos en -ote, -uсо, -uса, -ucho, -ucha, por ser de fácil formación y a menudo ocasional (Advertencias..., p. XXVII). Aunque no se hizo de una manera razonable, vid. Santos (1995). 
complementaria - por medio de marcas y de otro tipo de complementos al lado de la definición-y para ofrecer ejemplos en el diccionario, de manera similar a como hace cualquier otra obra lexicográfica que se caracterice por recoger este tipo de información 42 .

Pero también es importante señalar que con esa actitud se dé un paso, en algunos casos, en la organización de las acepciones que responda a la aplicación de un criterio de frecuencia de uso, como hemos tenido ocasión de comprobar, dando prioridad al valor calificativo sobre el relacional ${ }^{43}$. Claro que no faltan ejemplos en los que la primera acepción es la relacional, lo que no es más que una mera información etimológica, con la que en algunos casos, como hemos visto, se mezcla. Y parece que la necesidad de contar con esta definición - si es que se le puede llamar definición a la explicación que no deja de ser más que un recurso para ligar la base con el derivado-, se debe precisamente a la costumbre de que en este diccionario se organicen - contra sus propias normas - las acepciones con criterios cronológicos, etimológicos o morfológicos.

Quizás los grupos de adjetivos que he establecido confirmen la necesidad de avanzar en la dirección de ofrecer en todos los casos que sea conveniente información sintáctica o contextual e información pragmática, que permita hacer un adecuado uso de estas voces. En aquellos casos en los que estas restricciones no sean pertinentes y, además, sólo aparezca una acepción del tipo 'de+base' o 'perteneciente o relativo a' - que es etimológica y, por tanto, debe situarse en el lugar que le corresponde en la entrada lexicográfica-, lo razonable sería decidir la conveniencia de mantener o eliminar estas entradas del 
diccionario - al igual que se hizo en su momento con los adverbios terminados en -mente- 44 , en lo que la colocación de la acepción relacional al final de la entrada lexicográfica puede tomarse como un paso para su eliminación definitiva.

REFERENCIAS BIBLIOGRÁFICAS.

\section{A) Diccionarios utilizados:}

Academia Española (1726-1739): Diccionario de Autoridades. Madrid, Francisco del Hierro. (Edición facsímil, Madrid, Gredos, 1984).

Alvar EzQuerra, M. (dir) (1990): Diccionario General Ilustrado de la

Lengua Española, Barcelona, Vox Bibliograf, $1^{\mathrm{a}}$ edición, reimpresión de 1990 (citado DGILE'90).

Alvar EzQuerra, M. (dir) (1993): Diccionario General Ilustrado de la

Lengua Española, Barcelona, Vox Bibliograf (citado DGILE'93).

Alvar EzQuerra, M. (dir) (1995): Diccionario para la enseñanza de la lengua española, Madrid, Bibliograf-Universidad de Alcalá de Henares (citado Vox-Alcalá).

Gutiérrez Cuadrado, J. (dir.) [1996]: Diccionario Salamanca de la Lengua Española, Madrid, Editorial Santillana y Universidad de Salamanca.

Maldonado, C. (dir.) [1996]: Clave. Diccionario de Uso del Español Actual, Madrid, Ediciones SM.

Moliner, M. (1966): Diccionario de Uso del Español, Madrid, Gredos (citado DuE)

Real Academia Española (1984): Diccionario de la Lengua Española, Madrid, Espasa-Calpe, $20^{\mathrm{a}}$ edición (citado DRAE)

Real ACAdemia Española (1992): Diccionario de la Lengua Española, 
Madrid, Espasa-Calpe, $21^{\mathrm{a}}$ edición (citado DRAE).

RoBert, P. (1970): Dictionnaire Alphabétique \& Analogique de la Langue Française, París, Société du Nouveau Littré.

Vv.AA. (1996): Gran Diccionario de la Lengua Española. Barcelona, Larousse-Planeta (citado GDLE-Larousse Planeta).

\section{B) Estudios y artículos utilizados:}

Ahumada, I. (1987): “Contorno de la definición verbal y régimen lexemático: su indicación formal en la lexicografía hispánica”, en Amistad a lo largo. Estudios en memoria de J. Fernández Sevilla y N. Martín López, Granada, Universidad, pp. 13-25.

AHumada, I. (1988): "La información gramatical implícita en la definición lexicográfica", Thesaurus, 43, pp. 81-94.

Alonso Ramos, M. (1994): "Hacia una definición del concepto de colocación: de J.R. Firth a I.A. Mel'čuk”. Revista de Lexicografía, 1, pp. 9-28.

BARTOS, L. (1978): "Notas a la clasificación del adjetivo". Estudios ofrecidos a Emilio Alarcos Llorach, Oviedo, Universidad de Oviedo, vol. II, pp. 45-60.

BARTOS, L. (1995): "El llamado adjetivo relacional y su función en las unidades denominativas", en E. Nowikow (ed.), Lingüística Española. Aspectos sincrónicos y diacrónicos, Wroclaw, pp. 111-115.

BosQue, I. (1982): "Sobre la teoría de la definición lexicográfica", Verba, 9, pp. 105-123.

Bosque, I. (1989): Las categorías gramaticales, Madrid, Síntesis.

Bosque, I. (1993): "Sobre las diferencias entre los adjetivos relacionales y los calificativos", Revista Argentina de Lingüística, 9 (1-2), pp. $9-48$.

Bustos GisBert, E. (1986): La composición nominal en español, Salamanca, Universidad de Salamanca.

Cruse, D. A. (1986): Lexical Semantics, Cambridge, Cambridge University Press.

Demonte, V. (1982): "El falso problema de la posición del adjetivo: dos análisis semánticos", BRAE, 62, pp. 453-485.

ETTINGER, S. (1982): "La variación lingüística en lexicografía”, en Haens- 
ch, G. y otros (1982): La lexicografía. De la lingüística teórica a la lexicografía práctica, Madrid, Gredos.

Fernández Ramírez, S. (1986): Gramática española, ed. de J. Polo, Madrid, Arco Libros.

GawelKo, M. (1975): "Sur la classification sémantique des adjectifs suffixes", Lingua, 36, pp. 307-324.

HAUSMANN, F. J. (1979): "Un dictionnaire de collocations est-il possible?",

Travaux de Littérature et de Linguistique de l'Université de Strasbourg, 17 /1, pp. 187-195.

IMBS, P. (1969): "Les niveaux de langue dans le dictionnaire", Le français dans le Monde, 69, pp. 51-60.

KALIK, H. (1967): "L'expression des rapports de determiné à la determinant /adjectifs de relation/", Le Français Moderne, 35, pp. 270-285.

LAPESA, R. (1975): "La colocación del adjetivo atributivo en español", Homenaje a Antonio Rodríguez Moñino, Madrid, Castalia, pp. 329345.

LANG, M. (1992): Formación de palabras en español. Morfología derivativa productiva en el léxico moderno. Madrid, Cátedra (trad. de A. Miranda Poza).

PenA, J. (1994): “Formación de palabras, gramática y diccionario", Revista de Lexicografía, 1, pp. 163-180.

Pinchon, C. (1969): "L'adjectif de relation: formation et emploi", Le fraçais dans le Monde, 68, pp. 43-44

PINCHON, C. (1980): "Syntagme prépositionel et adjectif de relation", $\mathrm{Ca}-$ hiers de Lexicologie, 37, págs. 91-100.

Rojo, G. (1975): "Sobre la coordinación de adjetivos en la frase nominal y cuestiones conexas", Verba, 2, pp. 193-224.

SANTOS, L. (1995): Apuntes paralexicográficos. I. El diccionario como pretexto, Salamanca, Gráficas Varona, $2^{\mathrm{a}}$ edición.

Seco, M. (1987): Estudios de Lexicografía española, Madrid, Paraninfo.

Simón, C. (1979): "El problema de la colocación del adjetivo en castellano: revisión crítica del estado de la cuestión", Cuadernos de Filología de la Universidad de Valencia, II, pp. 183-198.

VARELA, S. (1992): Fundamentos de morfología, Madrid, Síntesis. 